\title{
Kinetics of enzyme-catalyzed cross-linking of feruloylated arabinan from sugar beet
}

\author{
Abang Zaidel, Dayang Norulfairuz; Arnous, Anis; Holck, Jesper; Meyer, Anne S.
}

Published in:

Journal of Agricultural and Food Chemistry

Link to article, DOI:

10.1021/jf203138u

Publication date:

2011

Document Version

Publisher's PDF, also known as Version of record

Link back to DTU Orbit

Citation (APA):

Abang Zaidel, D. N., Arnous, A., Holck, J., \& Meyer, A. S. (2011). Kinetics of enzyme-catalyzed cross-linking of feruloylated arabinan from sugar beet. Journal of Agricultural and Food Chemistry, 59, 11598-11607.

https://doi.org/10.1021/jf203138u

\section{General rights}

Copyright and moral rights for the publications made accessible in the public portal are retained by the authors and/or other copyright owners and it is a condition of accessing publications that users recognise and abide by the legal requirements associated with these rights.

- Users may download and print one copy of any publication from the public portal for the purpose of private study or research.

- You may not further distribute the material or use it for any profit-making activity or commercial gain

- You may freely distribute the URL identifying the publication in the public portal

If you believe that this document breaches copyright please contact us providing details, and we will remove access to the work immediately and investigate your claim. 


\title{
Kinetics of Enzyme-Catalyzed Cross-Linking of Feruloylated Arabinan from Sugar Beet
}

\author{
Dayang Norulfairuz Abang Zaidel, ${ }^{+, \S}$ Anis Arnous, ${ }^{\S}$ Jesper Holck, ${ }^{\S}$ and Anne S. Meyer ${ }^{*} \S$ \\ ${ }^{\dagger}$ Department of Bioprocess Engineering, Faculty of Chemical Engineering, Universiti Teknologi Malaysia, 81310 Skudai Johor, Malaysia \\ ${ }^{\S}$ Center for Bioprocess Engineering, Department of Chemical and Biochemical Engineering, The Technical University of Denmark, \\ 2800 Kgs. Lyngby, Denmark
}

ABSTRACT: Ferulic acid (FA) groups esterified to the arabinan side chains of pectic polysaccharides can be oxidatively crosslinked in vitro by horseradish peroxidase (HRP) catalysis in the presence of hydrogen peroxide $\left(\mathrm{H}_{2} \mathrm{O}_{2}\right)$ to form ferulic acid dehydrodimers (diFAs). The present work investigated whether the kinetics of HRP catalyzed cross-linking of FA esterified to $\alpha$-(1,5)-linked arabinans are affected by the length of the arabinan chains carrying the feruloyl substitutions. The kinetics of the HRP-catalyzed cross-linking of four sets of arabinan samples from sugar beet pulp, having different molecular weights and hence different degrees of polymerization, were monitored by the disappearance of FA absorbance at $316 \mathrm{~nm}$. MALDI-TOF/TOF-MS analysis confirmed that the sugar beet arabinans were feruloyl-substituted, and HPLC analysis verified that the amounts of diFAs increased when FA levels decreased as a result of the enzymatic oxidation treatment with $\mathrm{HRP}$ and $\mathrm{H}_{2} \mathrm{O}_{2}$. At equimolar levels of FA $(0.0025-0.05 \mathrm{mM})$ in the arabinan samples, the initial rates of the HRP-catalyzed cross-linking of the longer chain arabinans were slower than those of the shorter chain arabinans. The lower initial rates may be the result of the slower movement of larger molecules coupled with steric phenomena, making the required initial reaction of two FAs on longer chain arabinans slower than on shorter arabinans.

KEYWORDS: arabinan, dehydrodimers, ferulic acid, horseradish peroxidase kinetics

\section{INTRODUCTION}

Pectic polysaccharides extracted from sugar beet pulp mainly consist of homogalacturonan and rhamnogalacturon I (RGI), the latter notably being arabinan- and arabinogalactan-substituted RGI. ${ }^{1}$ As in other dicot plant cell walls the backbone of sugar beet RGI is made up of repeating units of $[\rightarrow 2)-\alpha$-LRhap- $(1 \rightarrow 4)-\alpha$-D-GalpA- $(1 \rightarrow] .^{2}$ The rhamnose moieties of the RGI in sugar beet pectin may be substituted at the $O-4$ position with $\alpha$-(1,5)-linked arabinans having a high degree of $\alpha$-(1,2)- and $\alpha$-(1,3)-arabinofuranosyl (Araf) substitutions and with minor amounts of $\beta$ - $(1,4)$-linked galactan. ${ }^{1,3}$ Some of the Araf moieties in the $\alpha-(1,5)$-linked arabinans are substituted with feruloyl groups, as single ferulic acid (FA) moieties or in the form of ferulic acid dehydrodimers (diFAs) that may even cross-link two different arabinan chains. ${ }^{4,5}$ The FA moieties are mainly esterified to the $O-2$ position of the Araf residues in the $\alpha$-(1,5)-linked arabinan backbone, but may also be bound to the $0-5$ on the terminal arabinose, ${ }^{4}$ or, to a much lesser extent, at the $0-6$ position of the galactopyranosyl ( $\mathrm{Gal} p$ ) residues in the $\beta$ - $(1,4)$-galactan chains. ${ }^{6}$

The FA bound to the side chains of pectic polysaccharides have long been known to have the ability to be oxidatively crosslinked via enzyme catalysis by oxidoreductases, that is, peroxidase or laccase activities. ${ }^{7,8}$ Previous work has shown that addition of, for example, peroxidase, together with $\mathrm{H}_{2} \mathrm{O}_{2}$ or laccase, results in a reduction of the amount of $\mathrm{FA}$ esterified to the arabinan chains while the levels of diFAs increase simultaneously. ${ }^{8,9}$ The enzymecatalyzed cross-linking of two feruloylated arabinan oligosaccharides takes place via radical coupling of the FA resulting in the formation of different diFAs: $5,5^{\prime}, 8-O-4^{\prime}, 8,5^{\prime}$, and $8,8^{\prime} .^{8-10}$ The formation of diFA cross-linking between feruloylated arabinans or feruloylated arabino-oligosaccharides may result in gel formation. ${ }^{1,8,11}$ Although studies on the oxidative cross-linking of feruloyl substitutions in polysaccharides have been amply reported, ${ }^{7-9}$ there are no reports on the effect of the length of the backbone of the arabinans on the rate of the cross-linking of feruloylated arabinan. Currently, the arabinan fraction from sugar beet pulp is a byproduct, but the utilization of the arabinan as a food additive could help maintain the competitiveness of the sugar beet based industry. Thus, the provision of knowledge regarding the crosslinking of feruloylated arabinan would, for example, be important for the rational design and control of enzymatic processes for upgrading sugar beet pulp arabinans for use as viscosity-regulating or gelling agents in foods and beverages.

We hypothesized that the rate of cross-linking of feruloylated arabinans obtained from sugar beet pulp might be affected by the backbone length of the arabinan to which the FA moieties are attached. Hypothetically, the rate of cross-linking between FA on longer arabinan chains is expected to be slower than the rate of cross-linking between FA on shorter arabinan chains mainly because of the relatively slower movement (diffusion) of larger molecules. However, once some initial diFAs formation has taken place with the longer chains, hence cross-linking two arabinan chains, the rates of diFA formation of long and short arabinan chains may approach each other because the diFAs on the longer chains will be in closer proximity, resulting in a sort of

Received: May 2, 2011

Revised: September 26, 2011

Accepted: September 28, 2011

Published: September 28, 2011 
A<smiles>OCCOCC1CCCC1C(O)O</smiles>

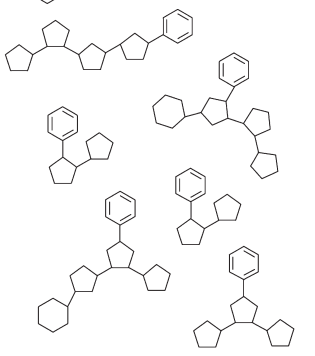

Peroxidase $/ \mathrm{H}_{2} \mathrm{O}_{2}$

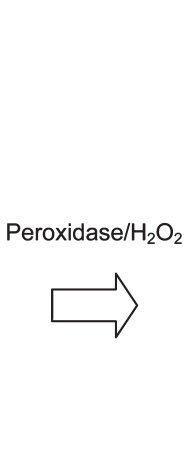

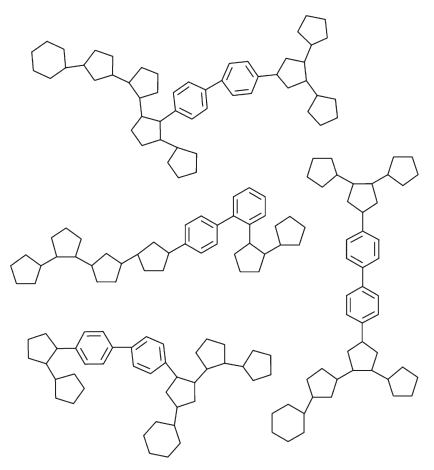<smiles>C1CCCCC1</smiles>

B<smiles>CCCCC=CCC(CCCC)C1CCCC1</smiles><smiles>C1CC1</smiles><smiles>C1CCCC2CCCC2CC1</smiles>

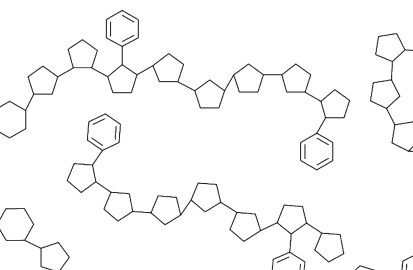<smiles>CCC</smiles>

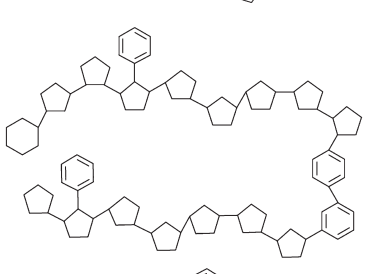<smiles>C1CCC2CCCC2C1</smiles>
Peroxidase $/ \mathrm{H}_{2} \mathrm{O}_{2}$

Second step cross linking<smiles>CC(COCc1ccccc1)OCCOc1ccccc1</smiles>

First step cross linking

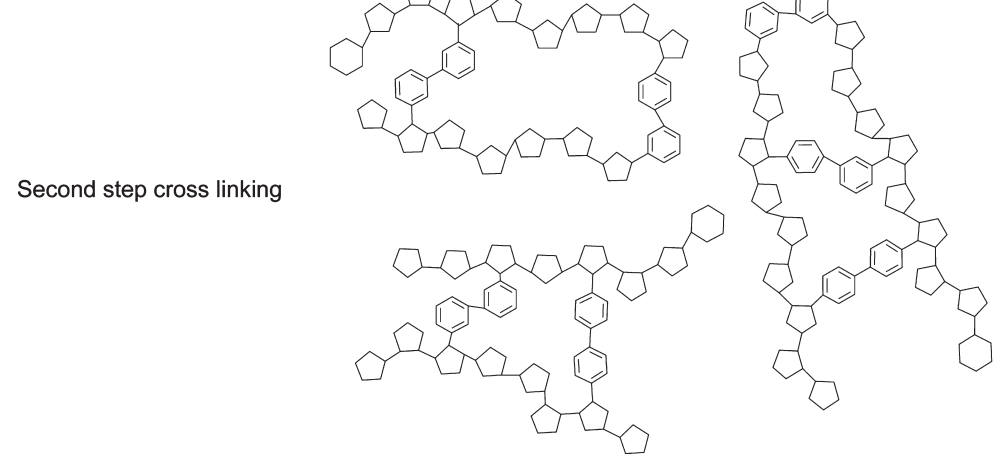

Figure 1. (A) Schematic representative structures of feruloylated arabinans from sugar beet pectin illustrating the one-step enzyme-catalyzed oxidative crosslinking model of short-chain arabinans. (B) Two-step enzyme-catalyzed oxidative cross-linking or "zipping" model for long-chain feruloylated arabinans.

"zipping" of the FA esterified to the arabinan chains (Figure 1). The purpose of this study was to test the hypothesis that the kinetics of the cross-linking of feruloylated arabinans is affected by the chain length of the arabinan. 


\section{MATERIALS AND METHODS}

Enzyme and Chemicals. Horseradish peroxidase (HRP) (EC 1.11.1.7) type VI-A, $1000 \mathrm{U} \mathrm{mg}^{-1}$, ferulic acid (4-hydroxy-3-methoxycinnamic acid) 99\%, isopropanol, sodium hydroxide $(\mathrm{NaOH})$ $50 \%(\mathrm{w} / \mathrm{w})$, ethyl acetate, acetonitrile, hydrogen peroxide $\left(\mathrm{H}_{2} \mathrm{O}_{2}\right)$ $50 \%(\mathrm{w} / \mathrm{w})$, sodium dihydrogen phosphate monohydrate $\left(\mathrm{NaH}_{2}-\right.$ $\mathrm{PO}_{4} \cdot \mathrm{H}_{2} \mathrm{O}$ ), trifluoroacetic acid (TFA) $98 \%(\mathrm{w} / \mathrm{w}$ ), pullulan standard with molecular weight of $1.3 \mathrm{kDa}$, and monosaccharide standards including D-galactose, L-arabinose, D-fucose, L-rhamnose monohydrate, and D-galacturonic acid monohydrate were purchased from Sigma-Aldrich Chemical Co. (St. Louis, MO). D-Glucose, D-xylose, anhydrous sodium sulfate $\left(\mathrm{Na}_{2} \mathrm{SO}_{4}\right)$, and disodium hydrogen phosphate $\left(\mathrm{Na}_{2} \mathrm{HPO}_{4}\right)$ were from Merck (Darmstadt, Germany). trans-Cinnamic acid 99\% was from Alfa Aesar $\mathrm{GmbH} \&$ Co. (Karlsruhe, Germany). Dextran standards with average molecular weights of 10 and $40 \mathrm{kDa}$, respectively, were from Pharmacia (Uppsala, Sweden). Arabino-oligosaccharide standards from DP2 to DP5 were purchased from Megazyme (Bray, Wicklow, Ireland).

Arabinan Raw Material. Arabinan samples were supplied by Danisco A/S (Nakskov, Denmark). The two batches of samples, Aral and Ara2, respectively, were two different permeate streams obtained from the preparation of pectin from sugar beet pulp via nitric acid hydrolysis involving removal of insoluble cellulose, ultrafiltration, and diafiltration with a $50 \mathrm{kDa}$ cutoff. ${ }^{2}$

Monosaccharide Composition of the Raw Material. The monosaccharide compositions of these starting materials were determined by high-performance anion exchange chromatography with pulsed amperometric detection (HPAEC-PAD) on a Dionex BioLC system (Dionex Corp., Sunnyvale, CA), after acid hydrolysis $\left(4 \mathrm{~g} \mathrm{~L}^{-1}\right.$ substrate, $2 \mathrm{M}$ TFA, $2 \mathrm{~h}, 121^{\circ} \mathrm{C}$ ) as described previously. ${ }^{12}$

Oligosaccharide Profiles of the Raw Materials. Separation and quantification of arabino-oligosaccharides were done by HPAECPAD using a Dionex BioLC system equipped with a CarboPac PA1 analytical column $(4 \times 250 \mathrm{~mm})$ controlled via Chromeleon $6.80 \mathrm{Sp} 8$ Build 2623 software (Dionex Corp.) as described in ref 13. In addition to arabinose, the arabino-oligosaccharide standards used were from DP2 to DP5.

Precipitation with Isopropanol. To obtain longer chain arabinan fractions, the Ara1 and Ara2 samples were treated with isopropanol in a 30:70 (v/v) water/isopropanol ratio and centrifuged at $9000 \mathrm{~g}$ for 15 min. In each case, the supernatant was discarded, and the pellet of the alcohol-insoluble longer chain arabinans was dried by evaporation under $\mathrm{N}_{2}$, then frozen, and lyophilized. The longer chain (feruloylated) arabinans from Aral were referred to as Aralb and the longer chain arabinans from Ara2 as Ara2b. Ara1b and Ara2b constituted approximately 3.5 and $4.5 \%$ of the weight of Ara1 and Ara2 after precipitation, respectively.

Phenolics Analysis. The contents of FA and diFAs were determined by reverse phase high-performance liquid chromatography (HPLC) after alkaline saponification (under nitrogen, $\mathrm{N}_{2}$ ) with $2 \mathrm{M}$ $\mathrm{NaOH}$ at $25{ }^{\circ} \mathrm{C}$, acidification, and triple ethyl acetate extraction as described previously. ${ }^{14,15}$ For each extracted sample, the ethyl acetate phases were pooled and water was removed by adding anhydrous $\mathrm{Na}_{2} \mathrm{SO}_{4}$. The pooled samples were dried under $\mathrm{N}_{2}$ at $30{ }^{\circ} \mathrm{C}$. Fifty percent $(\mathrm{v} / \mathrm{v})$ aqueous methanol was added to the samples that were then filtered using a $0.20 \mu \mathrm{m}$ nylon membrane filter (VWR International, USA). The sample $(40 \mu \mathrm{L})$ was injected into an HPLC Chemstation 1100 series equipped with an ODS-L Optimal $(250 \times$ $4.6 \mathrm{~mm}, 5 \mu \mathrm{m}$ ) column from Capital HPLC and a diode array detector (Hewlett-Packard, Palo Alto, CA). The gradient elution was performed using solvents A ( $5 \%(\mathrm{v} / \mathrm{v})$ acetonitrile, $1 \mathrm{mM} \mathrm{TFA})$ and B (acetonitrile) starting with $20 \%(\mathrm{v} / \mathrm{v})$ acetonitrile at $0.5 \mathrm{~mL} \mathrm{~min}^{-1}$. The gradient was run up to $40 \%(\mathrm{v} / \mathrm{v})$ acetonitrile for $35 \mathrm{~min}$ and further up to $100 \%$ for another $3 \mathrm{~min}$, with a final regeneration to $20 \%(\mathrm{v} / \mathrm{v})$ acetonitrile for 2 min. $^{16}$ The column temperature was maintained at $40{ }^{\circ} \mathrm{C}$. FA was detected and quantified at $316 \mathrm{~nm}$ using an authentic external standard for retention time and spectral recognition; quantification was by area linear regression. diFAs were also detected at $316 \mathrm{~nm}$ but quantified at $280 \mathrm{~nm}$ according to response factors as described in ref ${ }^{17}$. Due to differences in sensitivity between HPLC and spectrophotometry, higher sample concentrations $\left(50 \mathrm{~g} \mathrm{~L}^{-1}\right)$ were used for the HPLC analysis.

Size Exclusion Chromatography (HPSEC). HPSEC was performed using a system consisting of a P680 HPLC pump, an ASI-100 automated sample injector, and an RI-101 refractive index detector (Dionex Corp.). Lyophilized arabinan samples were redissolved and diluted in $0.1 \mathrm{M}$ sodium acetate buffer $(\mathrm{pH} 6)$ and filtered with a syringe through a $0.20 \mu \mathrm{m}$ nylon membrane filter (VWR International, USA). The sample $(25 \mu \mathrm{L})$ was injected and separated using a Shodex SB-806 HQ OHpak column $(300 \times 8 \mathrm{~mm})$ with a Shodex SB-G guard column $(50 \times 6 \mathrm{~mm})$ (Showa Denko K.K., Tokyo, Japan) and eluted with $0.1 \mathrm{M}$ sodium acetate buffer $(\mathrm{pH} 6)$ at $30^{\circ} \mathrm{C}$ and a flow rate of $0.5 \mathrm{~mL} \mathrm{~min}^{-1} .18$ Standards were a monomer (arabinose), pullulan standard with a molecular weight of $1.3 \mathrm{kDa}$, and dextran standards with molecular weights of 10 and $40 \mathrm{kDa}$, respectively.

Analysis of Feruloylated Arabino-oligosaccharides by Hydrophilic Interaction Chromatography (HILIC). Lyophilized (feruloylated) arabinan samples were suspended in deionized water followed by cleanup using $70 \%$ (v/v) final concentration of acetonitrile. The acetonitrile cleanup step was included to eliminate the noise from the presence of peptides and polar compounds prior to chromatographic separation of the arabinan samples. Acetonitrile (70\% (v/v)) treated samples were immediately centrifuged for $3 \mathrm{~min}$ at $16000 \mathrm{~g}$, and each supernatant was then injected $(10 \mu \mathrm{L})$ into the HILIC system. The HILIC separation of the feruloylated arabinans according to hydrophilic interaction was performed using an ICS-3000 system coupled to a photodiode array detector (PDA-100) (Dionex Corp.) and equipped with a TSKgel Amide- 80 column $(250 \times 4.6 \mathrm{~mm}$ i.d., $5 \mu \mathrm{m}$, Tosoh Bioscience) at $55^{\circ} \mathrm{C}$. The eluent system consisted of three components (A, acetonitrile; B, deionized water containing $1 \%$ (v/v) TFA; C, deionized water) that were delivered in a gradient at a flow rate of $1 \mathrm{~mL} \mathrm{m^{-1 }}$. The gradient was run from $75 \%(\mathrm{v} / \mathrm{v})$ of A and $25 \%(\mathrm{v} / \mathrm{v})$ of $\mathrm{B}$ to $25 \%(\mathrm{v} / \mathrm{v})$ of $\mathrm{A}$ and $75 \%(\mathrm{v} / \mathrm{v})$ of $\mathrm{B}$ for $35 \mathrm{~min}$ and then run at $100 \%$ of $C$ for $2 \mathrm{~min}$. The gradient was then returned to $75 \%$ (v/v) of $A$ and $25 \%(\mathrm{v} / \mathrm{v})$ of B for the final $2 \mathrm{~min}$ for reconditioning. Feruloylated compounds were detected and quantified by UV absorption at $316 \mathrm{~nm}$ using ferulic acid as external standard.

MALDI-TOF/TOF Analysis. Mass spectrometric analyses of the arabinan samples were performed on a 4800 Plus MALDI TOF/TOF (AB SCIEX) mass spectrometer. The sample $(0.5 \mu \mathrm{L})$ was deposited onto a stainless steel MALDI target with $0.5 \mu \mathrm{L}$ of the matrix ( $\alpha$-cyano4-hydroxycinnamic acid from Sigma-Aldrich (St. Louis, MO)) and dried. The matrix was prepared at a concentration of $10 \mathrm{mg} \mathrm{mL}^{-1}$ in a $70 \% \mathrm{ACN} / 0.1 \% \mathrm{TFA} /$ water $(\mathrm{v} / \mathrm{v})$ solution. The instrument was operated in positive ion reflector mode, and the $\mathrm{m} / z$ range from 100 to 3500 was monitored. A total of 1000 laser shots were applied to each sample in MS mode. In MS/MS mode 2000 shots were obtained. The laser intensity was manually varied to obtain the best possible spectra (MS, from 4500 to 4800; MS/MS, from 4800 to 5100). MALDI-TOFMS and MS/MS data were exported as text files using DataExplorer (version 4.0). Each spectrum were smoothed, labeled, and analyzed manually in M/Z (Genomic Solutions).

Cross-Linking Kinetics. Stock solutions of $10 \mathrm{mg} \mathrm{L}^{-1} \mathrm{HRP}$ and $85 \mu \mathrm{M} \mathrm{H}_{2} \mathrm{O}_{2}$, respectively, were prepared in $0.1 \mathrm{M}$ sodium phosphate buffer, $\mathrm{pH} 6$ (both were made fresh every day). Reaction mixtures for the cross-linking were prepared by adding $\mathrm{H}_{2} \mathrm{O}_{2}(14 \mu \mathrm{M})$ and $\mathrm{HRP}$ $\left(0.2 \mathrm{mg} \mathrm{L}^{-1}=0.2 \mathrm{U} \mathrm{mL}^{-1}\right)$ to different defined FA concentrations $(0.0025-0.05 \mathrm{mM})$ of the feruloylated arabinan samples. After preliminary 
Table 1. Total Ferulic Acid and Diferulates Content in Arabinan Samples before and after Cross-Linking Using $\mathrm{HRP}_{\text {and }} \mathrm{H}_{2} \mathrm{O}_{2}$ Analyzed Using RP-HPLC ${ }^{a}$

\begin{tabular}{|c|c|c|c|c|}
\hline \multirow[b]{2}{*}{ sample } & \multicolumn{2}{|c|}{ FA ( $\mathrm{mg} \mathrm{g}^{-1}$ dry matter) } & \multicolumn{2}{|c|}{ total diFAs ${ }^{b}\left(\mathrm{mg} \mathrm{g}^{-1}\right.$ dry matter) } \\
\hline & before cross-linking & after cross-linking & before cross-linking & after cross-linking \\
\hline Aral & $7.0 \pm 0.5$ & $2.4 \pm 0.2$ & $2.4 \pm 0.6$ & $5.1 \pm 1.3$ \\
\hline Ara2 & $2.5 \pm 0.6$ & $1.4 \pm 0.3$ & $2.32 \pm 0.03$ & $2.82 \pm 0.04$ \\
\hline Aralb & $2.4 \pm 0.5$ & $0.29 \pm 0.06$ & $0.44 \pm 0.04$ & $1.01 \pm 0.08$ \\
\hline Ara2b & $1.1 \pm 0.2$ & $0.1 \pm 0.01$ & $0.6 \pm 0.2$ & $0.30 \pm 0.02$ \\
\hline
\end{tabular}

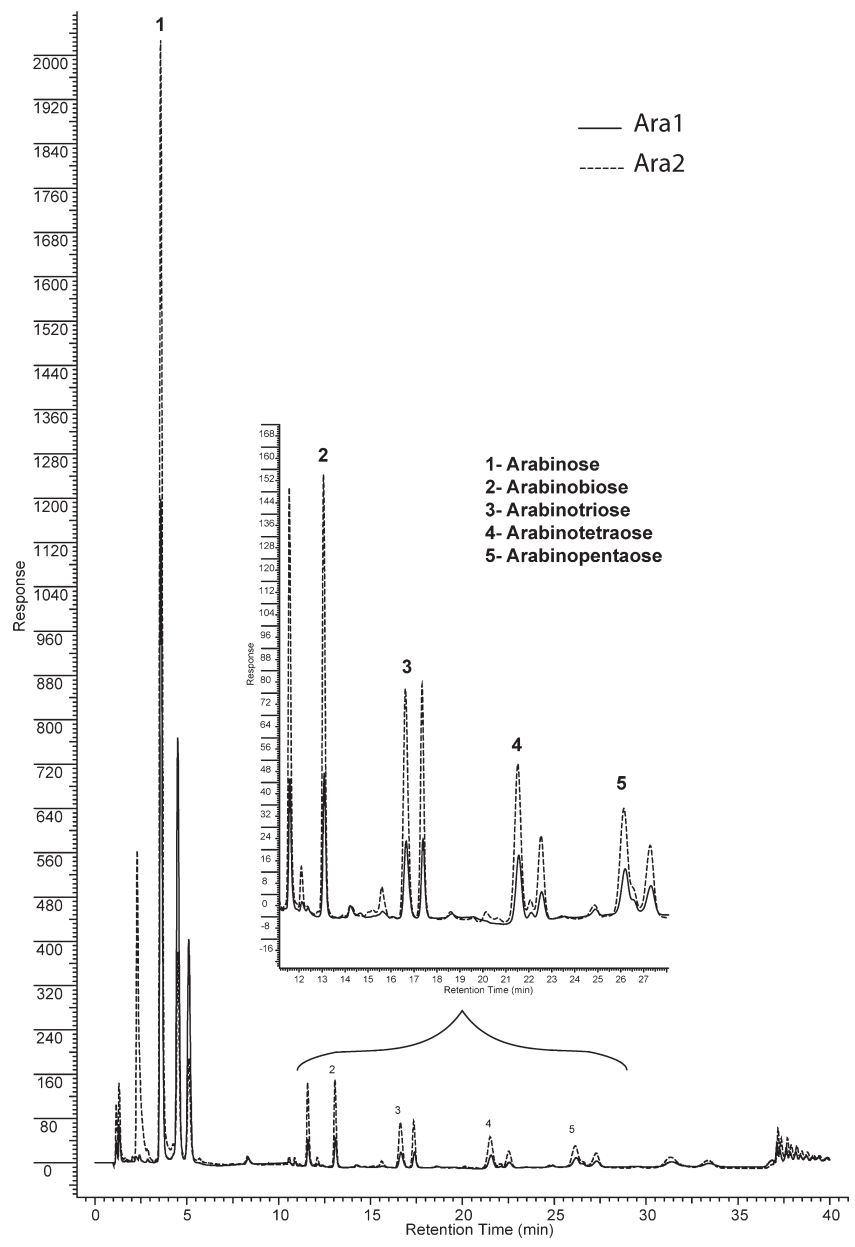

Figure 2. Arabino-oligosaccharide profiles of the feruloylated sugar beet pulp arabinan samples Ara1 and Ara2 as analyzed by HPAEC. The numbers over the peaks represent $\alpha$-(1,5)-arabinose to $\alpha$-(1,5)arabinopentaose.

runs, an amount of $\mathrm{H}_{2} \mathrm{O}_{2}(14 \mu \mathrm{M})$ was determined to be moderate and sufficient for all of the measurements within the FA concentrations range (0.0025-0.05 mM) of this cross-linking experiment. In blanks, the enzyme solution was substituted with $0.1 \mathrm{M}$ sodium phosphate buffer, $\mathrm{pH}$ 6. The cross-linking reaction was monitored by the disappearance of FA at an absorbance of $316 \mathrm{~nm}$ at $25{ }^{\circ} \mathrm{C}$ for $20 \mathrm{~min}$ in a Lambda20 UV-vis spectrophotometer (PerkinElmer Inc., USA). For analysis of FA and diFAs content by HPLC after the reaction, the reaction $(1 \mathrm{~mL})$ was stopped by the addition of $2 \mathrm{M} \mathrm{NaOH}(1 \mathrm{~mL})$ and extracted as described above. For each cross-linking experiment the reactions were run in duplicate, and hence the

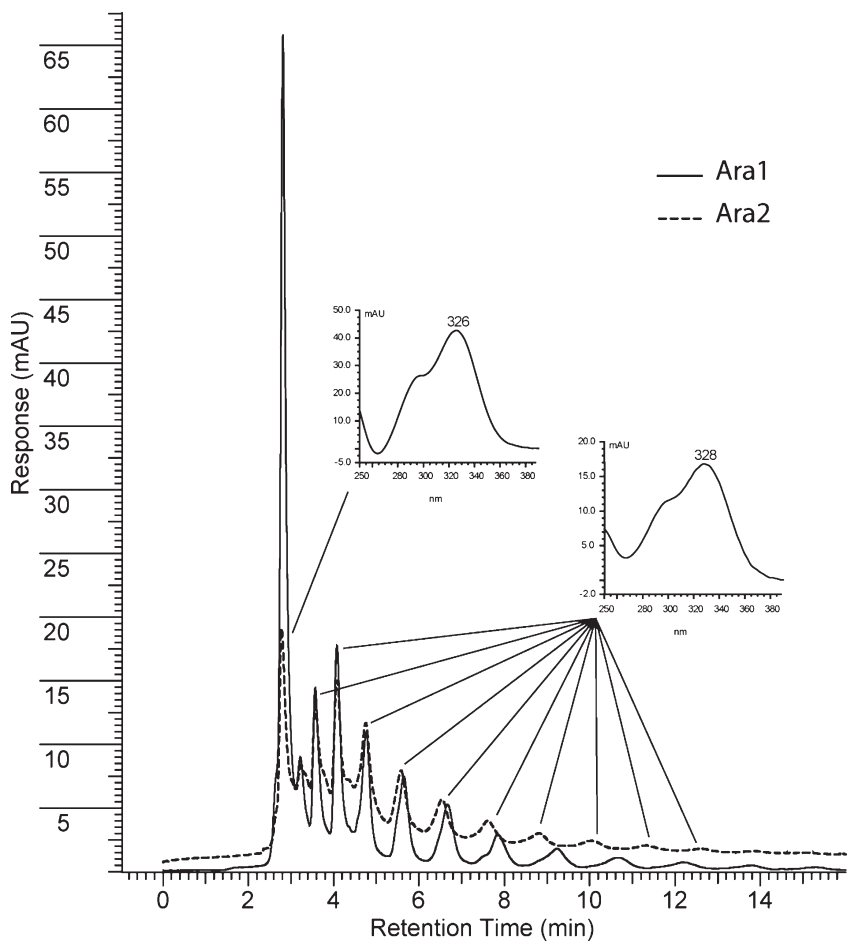

Figure 3. HILIC gradient chromatogram illustrating the presence of trans-feruloyl groups attached to sugar beet pulp derived arabinan oligosaccharides of different lengths eluting in the order of chain length, shorter first. The FA was detected at $316 \mathrm{~nm}$, but the peak of the spectra reached the maximum at $326-328 \mathrm{~nm}$.

recordings of the absorbance were given as the average value \pm standard deviation of two replicate runs.

Statistics. One-way analyses of variances (one-way ANOVA; 95\% confidence intervals) were compared as Tukey-Kramer intervals calculated from pooled standard deviations (Minitab Statistical Software, Addison-Wesley, Reading, MA).

\section{RESULTS AND DISCUSSION}

Composition of Sugar Beet Arabinan Substrates. The monosaccharide profiles of the starting materials, Aral and Ara2, confirmed that the substrates could be classified as arabinans, and Aral has also been characterized previously. ${ }^{19}$ Their compositions (in mmol g ${ }^{-1}$ dry matter) were as follows: for Ara1, arabinose, 3.4 (equivalent to $88 \mathrm{~mol} \%$ ); glucose, 0.27 (equivalent to $7 \mathrm{~mol} \%$ ), with traces of $<1 \mathrm{~mol} \%$ of rhamnose, galactose, and galacturonic acid; for Ara2, arabinose, 2.9 

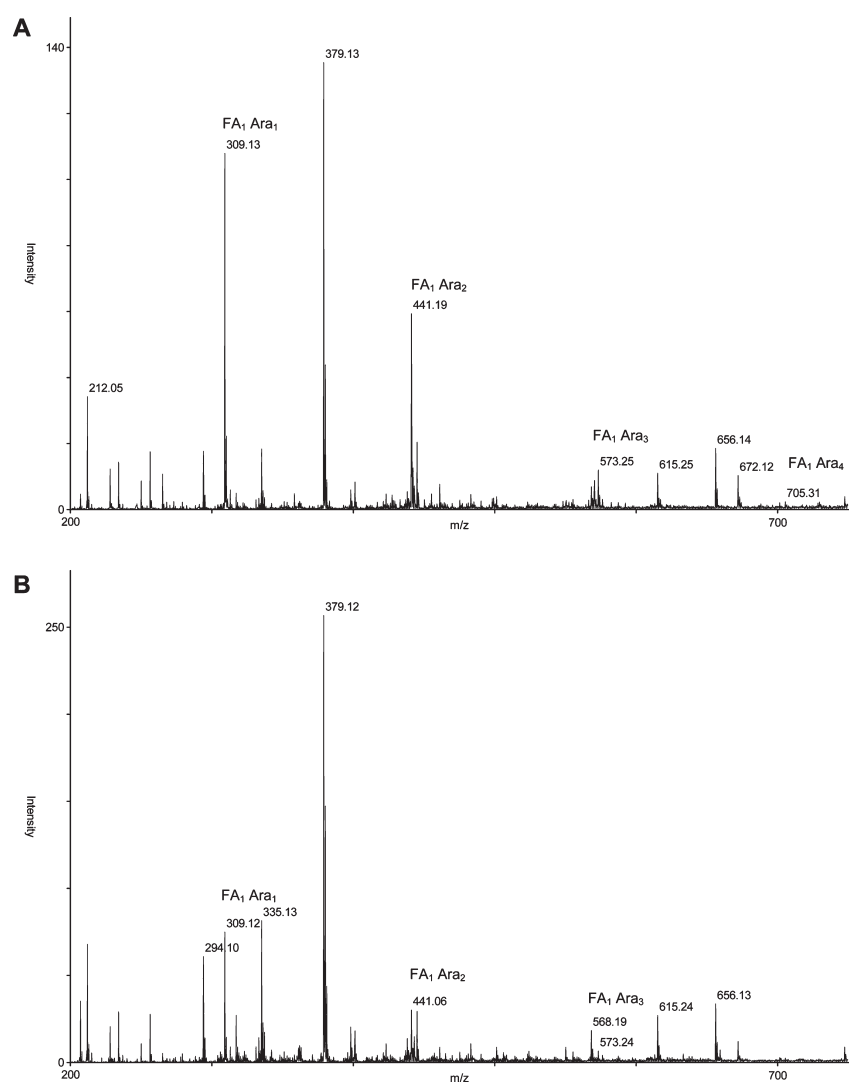

Figure 4. Mass spectra from MALDI-TOF analysis of (A) Aral and (B) Ara2. (equivalent to $95 \mathrm{~mol} \%$ ) and traces of $<1 \mathrm{~mol} \%$ of rhamnose, glucose, galactose, and galacturonic acid. The total FA content in the four different arabinan samples ranged from 1.1 to $7.0 \mathrm{mg} \mathrm{g}^{-1}$ dry matter arabinan (Table 1). Aral contained the highest amount of FA esterified to the arabinan $\left(7.0 \pm 0.5 \mathrm{mg} \mathrm{g}^{-1}\right)$ followed by Ara2 $\left(2.5 \pm 0.6 \mathrm{mg} \mathrm{g}^{-1}\right)$, Ara1b $\left(2.4 \pm 0.5 \mathrm{mg} \mathrm{g}^{-1}\right)$, and Ara2b $\left(1.1 \pm 0.2 \mathrm{mg} \mathrm{g}^{-1}\right.$ ) (Table 1). Hence, the extent of feruloyl substitution was apparently $50-60 \%$ less in the longer chain arabinan samples than in the starting material. The molar ratio of FA to arabinose (FA:Ara) in the samples was calculated to be 1:90 (Ara1), 1:200 (Ara2), 1:40 (Ara1b), and 1:20 (Ara2b). Naturally occurring diFAs made up 2.4 and $2.3 \mathrm{mg} \mathrm{g}^{-1}$ of the Ara 1 and Ara2 samples and 0.44 and $0.60 \mathrm{mg} \mathrm{g}^{-1}$ of Aralb and Ara2b, respectively (Table 1 ). Other naturally occurring diFAs such as $8,8^{\prime}$ and $4-O-5^{\prime}$-diFAs were not detected in the samples, most probably due to very low concentrations in different species of sugar beet or loss due to the extraction conditions.

Arabino-oligomer Profile of the Arabinan Substrates. Analysis by HPAEC indicated that Ara1 and Ara2 mainly consisted of short DP arabino-oligomers, including mainly monomers (notably arabinose) and $\alpha$-(1,5)-arabino-oligosaccharides up to DP5 (arabinopentaose), with the Ara2 being relatively richer in all of the detected short oligomers, including the monosaccharide peak, when evaluated at the same dry matter concentration (Figure 2). The peaks of Ara $1 \mathrm{~b}$ and Ara2b eluted similarly to Ara1 and Ara2 but at much lower levels (approximately $7-15 \%$ of Ara1 and Ara2) when analyzed at $1 \mathrm{~g} \mathrm{~L}^{-1}$ for DP2-DP4, but the large MW molecules escaped this analysis (data not shown). The HPAEC spectra also revealed triple peaks, of which the latest eluted peak in each set was
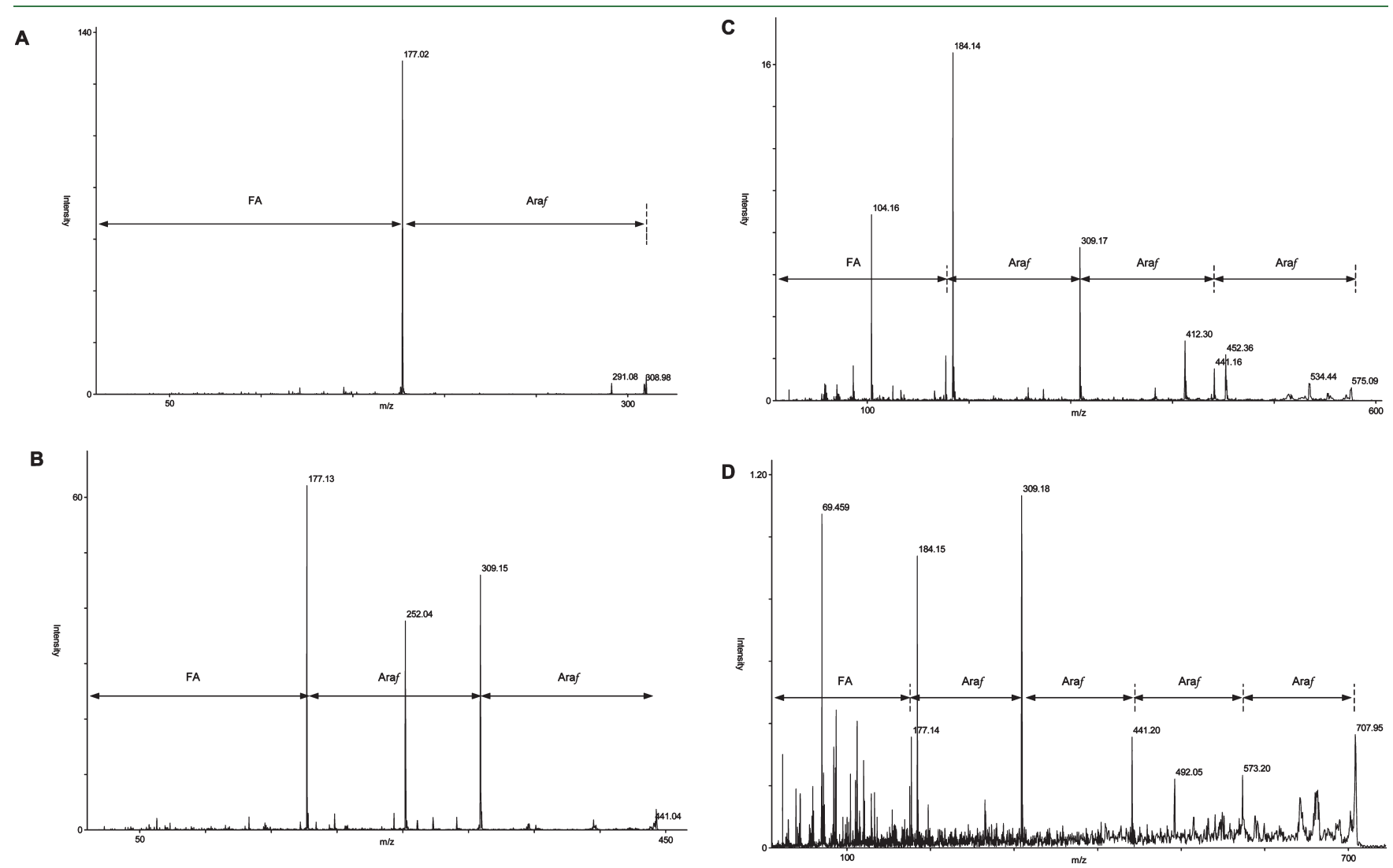

Figure 5. MS/MS spectra for arabinan oligosaccharides for ions at $m / z$ (A) 309, (B) 441, (C) 573, and (D) 705 of Ara1. 


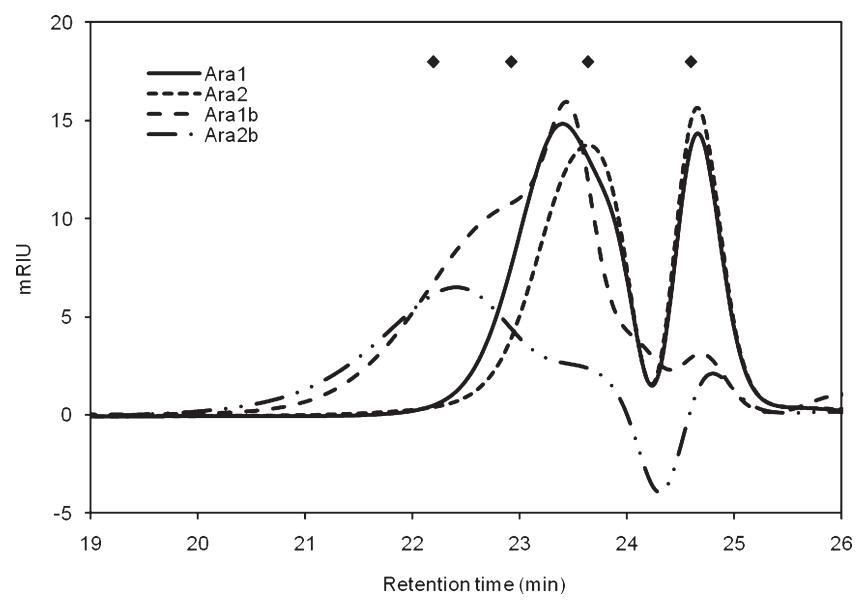

Figure 6. HPSEC chromatogram for Ara1, Ara2, Ara1b, and Ara2b. Standards $(\diamond)$, from left to right: $40 \mathrm{kDa}, 10 \mathrm{kDa}, 1.3 \mathrm{kDa}$, and $150 \mathrm{Da}$ (arabinose).

unidentifiable, except for the latest peak designated peak 2 in the first triplet oligomer peak set, which was identified as $\alpha$-(1,5)-arabinobiose from the elution of an authentic standard (Figure 2). With the extent of feruloyl substitution of $\sim 1: 90$ and $\sim 1: 200$ in Ara1 and Ara2 (Table 1), respectively, it seems unlikely that the "additional" peaks were due to the feruloyl substitutions. Rather, the triplet sets of peaks may be a result of branched arabino-oligosaccharides because sugar beet pectin is rich in those and branched arabino-oligosaccharides are known to elute slightly differently from the corresponding (same number of monomers) linear arabino-oligosaccharides. ${ }^{3}$ For disaccharides, the different retention times may be due to different glycosyl-linkage positions of the arabinooligosaccharides. Therefore, because the peak labeled 2 was the $\alpha$-(1,5)-arabinobiose, it is suggested that there was an approximately equal amount of $\alpha$-(1,3)-arabinobiose, whereas the third smaller peak between these two peaks might indicate a small amount of $\alpha$ - $(1,2)$-arabinobiose. However, a further analysis with different standards is needed to confirm this result.

Feruloyl Group Distribution. The UV - vis spectra from HILIC separation confirmed the identity of the FA attached to different arabino-oligosaccharide chains (Figure 3) as also reported previously. ${ }^{19}$ The amide stationary phase provided a unique selectivity for the arabino-oligosaccharides under HILIC as the hydrogen-bonding retention mechanism between hydroxyl groups of the oligosaccharides and the carbamoyl group in the stationary phase made it possible to elute different chain lengths based on the oligosaccharide chains' polarity and degree of solvation.

MALDI-TOF-MS analysis of the Ara1 and Ara2 samples confirmed the structural makeup of the substrates with the series of peak signals at $\mathrm{m} / z 309,441,573$, and 705 , corresponding to a series of "dehydrated" arabinose (Araf) moieties (of $132 \mathrm{Da}$ ) with a single feruloyl ester substitution $(m / z$ 177) (Figure 4). The fragmentation pattern thus revealed the formation of $\mathrm{C}$ type ions corresponding to loss of arabinose moieties. Because the MS/MS analysis was performed in positive mode, protonated $[\mathrm{M}+\mathrm{H}]^{+}$adducts were formed, measuring ferulic acid as $176+1$ : $m / z=177$. The structure was confirmed by MS/MS fragmentation as exemplified with $m / z 441$ (Figure 5). The MS/MS data could not, however, determine the degree of branching or the
Table 2. Ferulic Acid (FA) Content per Amount of Dry Matter (DM) Arabinan in the Samples Used for Cross-Linking of (Feruloylated) Arabinan Samples with HRP and $\mathrm{H}_{2} \mathrm{O}_{2}$ Treatment ${ }^{a}$

$\begin{array}{ccccc}\text { sample } & \begin{array}{c}\text { FA } \\ (\mathrm{mM})^{b}\end{array} & \begin{array}{c}\text { dry matter } \\ \left(\mathrm{g} \mathrm{L}^{-1}\right)\end{array} & \begin{array}{c}\mathrm{FA}^{c} \\ (\mu \mathrm{M})\end{array} & \begin{array}{c}\mathrm{FA} / \mathrm{DM} \\ \left(\mathrm{mg} \mathrm{g}^{-1}\right)\end{array} \\ \text { Ara1 } & 0.010 & 0.19 & 9.87 \pm 0.01 & 9.87 \pm 0.01 \\ & 0.020 & 0.40 & 20.72 \pm 0.01 & 10.04 \pm 0.01 \\ & 0.030 & 0.61 & 32.10 \pm 0.01 & 10.26 \pm 0.01 \\ & 0.040 & 0.81 & 43.37 \pm 0.03 & 10.35 \pm 0.01 \\ & 0.050 & 1.02 & 57.43 \pm 0.04 & 10.93 \pm 0.01 \\ & & & & \\ \text { Ara2 } & 0.0025 & 0.08 & 5.81 \pm 0.02 & 15.1 \pm 0.1 \\ & 0.005 & 0.10 & 8.80 \pm 0.10 & 14.6 \pm 0.1 \\ & 0.010 & 0.20 & 15.8 \pm 0.2 & 15.2 \pm 0.1 \\ & 0.020 & 0.40 & 30.5 \pm 0.2 & 15.9 \pm 0.1 \\ & 0.045 & 0.80 & 63.4 \pm 0.2 & 15.4 \pm 0.1 \\ & & & & \\ \text { Ara1b } & 0.010 & 0.20 & 14.0 \pm 0.3 & 13.6 \pm 0.3 \\ & 0.020 & 0.47 & 37.3 \pm 0.4 & 15.5 \pm 0.2 \\ & 0.030 & 0.73 & 54.7 \pm 0.3 & 14.5 \pm 0.1 \\ & 0.040 & 1.00 & 75.8 \pm 0.1 & 14.7 \pm 0.02 \\ & & & & \\ \text { Ara2b } & 0.0025 & 0.004 & 0.27 \pm 0.03 & 12.7 \pm 1.6 \\ & 0.005 & 0.06 & 2.11 \pm 0.03 & 7.20 \pm 0.10 \\ & 0.010 & 0.16 & 11.2 \pm 0.7 & 13.4 \pm 0.9\end{array}$

${ }^{a}$ Results are shown as mean \pm SD for samples analyzed as duplicates.

${ }^{b}$ Initial FA value. ${ }^{c}$ FA measured by absorbance measurement at $316 \mathrm{~nm}$.

Table 3. Initial Rate for Oxidative Cross-Linking Ara1 and Ara2 at Various Enzyme Dosages of HRP at $30 \mu \mathrm{M}$ FA Equivalents in Arabinan Samples

\begin{tabular}{ccc} 
& \multicolumn{2}{c}{ initial rate $\left(\mu \mathrm{M} \mathrm{min}^{-1}\right)$} \\
\cline { 2 - 3 } $\operatorname{HRP}\left(\mathrm{U} \mathrm{mL}^{-1}\right)$ & \multicolumn{1}{c}{ Ara1 } & Ara2 \\
0.1 & $5.7 \pm 0.3$ & $3.1 \pm 0.5$ \\
0.2 & $9.7 \pm 0.2$ & $5.1 \pm 0.3$ \\
0.4 & $11.4 \pm 0.8$ & $7.3 \pm 0.1$ \\
0.6 & $11.1 \pm 0.7$ & $7.5 \pm 0.1$ \\
\hline
\end{tabular}

exact points of feruloyl substitution on each type of molecule, because molecules with different substitution patterns have the same fragmentation pattern. ${ }^{19}$ In a separate study further purification of the Aral arabinan sample has revealed that this sample also contained arabino-oligosaccharide series (DP7-14) with double feruloyl substitutions. ${ }^{19}$ No feruloyl substitutions on galactose residues were detected. Neither were any diFAs detected by MS/MS, even though the HPLC analysis indicated their presence (Table 1).

Determination of Molecular Weight. HPSEC analysis showed that Ara1 and Ara2 gave dual peaks with one peak at $\sim 24.5$ min corresponding to monomers and an earlier peak at $\sim 23.5 \mathrm{~min}$ (Figure 6). These peaks were shaped differently for Ara1 and Ara2, corresponding to molecular weights somewhat higher than $1.3 \mathrm{kDa}$ for Ara1 and $\sim 1.3 \mathrm{kDa}$ for Ara2 (Figure 6). The SEC profile of Aralb showed that this sample contained 

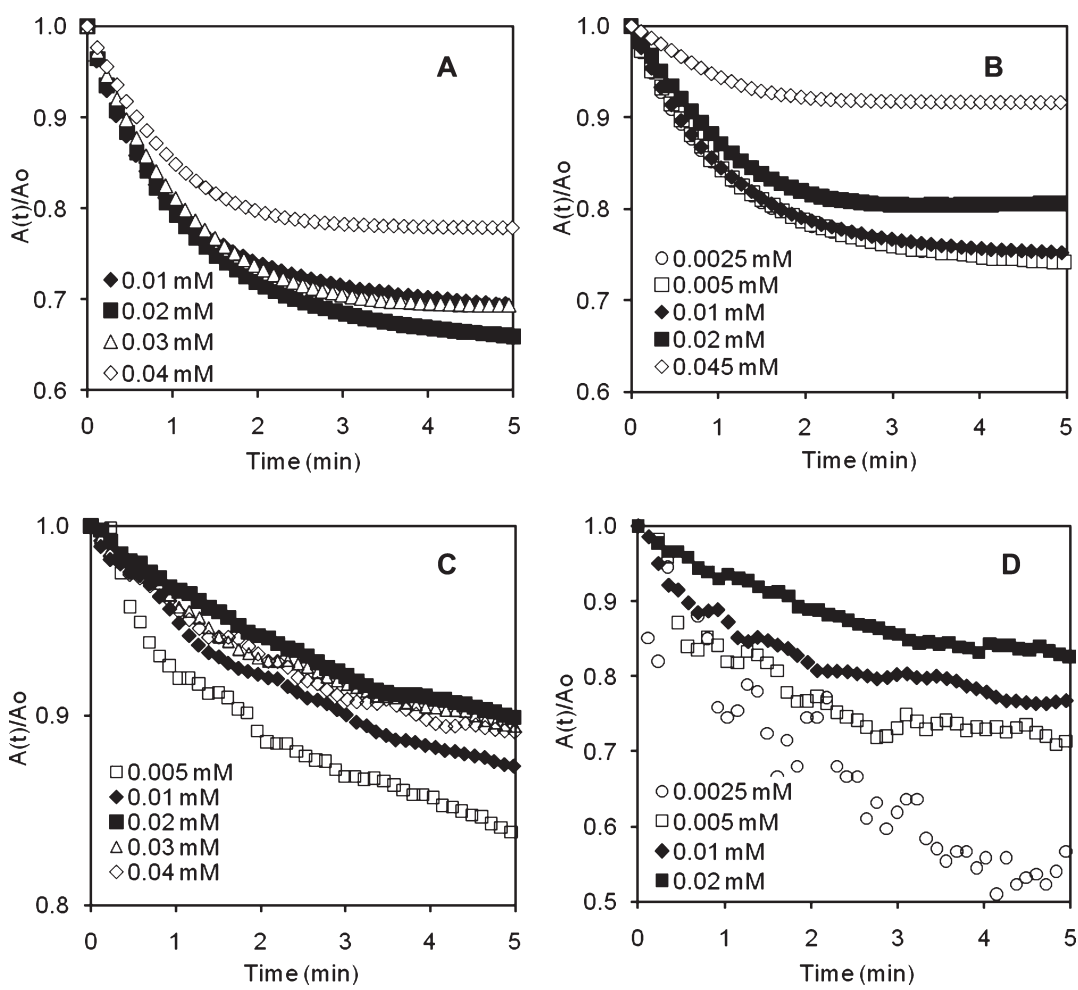

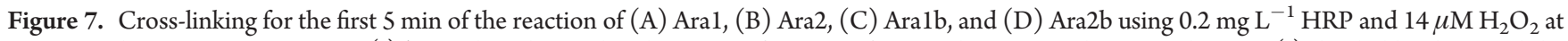
various arabinan concentrations. $A(t) / A_{0}$ is the relative absorbance as a function of time: $\mathrm{Abs}_{316 \mathrm{~nm}}$ at the particular time $(t)$ divided by the initial the $\mathrm{Abs}_{316 \mathrm{~nm}}$ at time 0 .

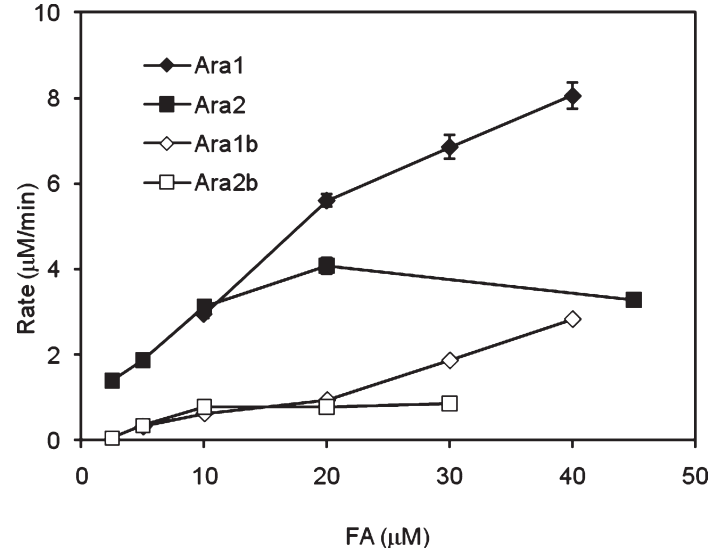

Figure 8. Initial rate of enzyme-catalyzed oxidative cross-linking of FA in feruloylated arabinans. Rate was calculated during the first $10 \mathrm{~s}$ of the reaction for the original arabinan samples, Ara1 and Ara2, and during the first minute of enzyme-catalyzed reaction for the longer chain arabinans, Aralb and Ara2b.

larger molecular weight polysaccharides eluting broadly from 22 to $24 \mathrm{~min}$ with a shoulder on the peak with a maximum at $\sim 23.5$ min indicating molecular weights around and above $1.3 \mathrm{kDa}$. The Ara2b contained relatively more of the larger molecular weight polysaccharides than Aralb with a broad peak eluting mainly around $22 \mathrm{~min}$ (Figure 6). Hence, the SEC profile confirmed that larger molecules, that is, longer chain arabinans, were extracted from the samples by the isopropanol precipitation and also revealed that Aral and
Ara2 contained slightly differently sized arabinan and arabinooligosaccharides around $1.3 \mathrm{kDa}$ and above.

Cross-Linking Kinetics of Feruloylated Arabinan. To ensure that the rate of cross-linking was not affected by the different levels of FA in the different arabinan samples, the cross-linking experiments were compared at equimolar FA levels (0.0025$0.050 \mathrm{mM}$ ), but with slightly different levels in the different samples designed to achieve significant differences in the reaction rates (Table 2). The enzyme-catalyzed oxidative cross-linking experiments were done at $25^{\circ} \mathrm{C}$ and pH 6 with $14 \mu \mathrm{M} \mathrm{H}_{2} \mathrm{O}_{2}$ and $0.2 \mathrm{mg} \mathrm{L}^{-1} \mathrm{HRP}$ (equivalent to $0.2 \mathrm{U} \mathrm{mL}^{-1}$ ) as defined from preliminary experiments as being the optimal conditions of reaction for monitoring the rate of the HRP-catalyzed reaction (Table 3). At this concentration the changes in absorbance took place at moderate rates, allowing for precise absorbance measurement after the addition of the HRP into the reaction mixture. The level of $\mathrm{H}_{2} \mathrm{O}_{2}$ was sufficient for the cross-linking as a higher concentration of $\mathrm{H}_{2} \mathrm{O}_{2}$ did not increase the rate (data not shown). Rather, a higher concentration of $\mathrm{H}_{2} \mathrm{O}_{2}$ may lead to partial inactivation of the enzyme. ${ }^{20}$ In general, for the Aral and Ara2, the relative absorbance at $316 \mathrm{~nm}$ decreased steeply at the beginning of the reaction (from 0 to $1 \mathrm{~min}$ ) and then decreased more gradually until it reached a pseudosteady state (Figure 7A,B). Presumably, at this point there were still some FA groups left that were unable to react to form the diFAs. The corresponding slopes of the reactions of the longer chain arabinan samples, Aralb and Ara2b, were much lower, indicating relatively slower consumption of the FA as compared to the consumption in the shorter arabinans at the same FA concentrations (Figure 7C,D).

Rates of Cross-Linking of Different Arabinan Sizes. Due to the different initial absorbances of the different substrate concentrations, 

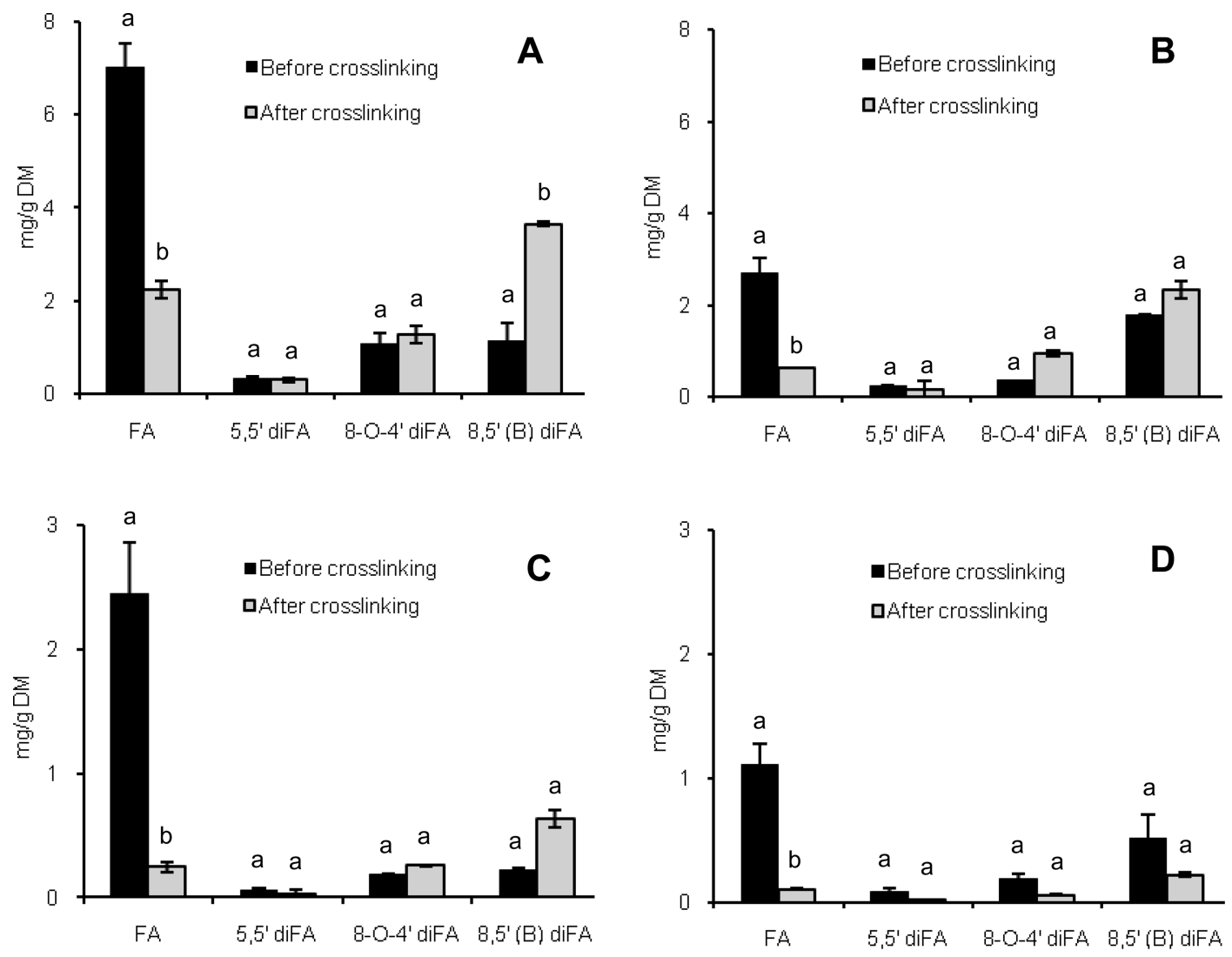

Figure 9. Profile of FA and diFAs after the addition of HRP and $\mathrm{H}_{2} \mathrm{O}_{2}$ in (A) Ara1, (B) Ara2, (C) Aralb, and (D) Ara2b. Error bars are SD from duplicate measurements. Different letters (a, b) within each set of comparison of the content (before and after cross-linking) indicate statistically significant difference at $P<0.05$ using one-way ANOVA. Pooled SDs were (A) 0.4231, (B) 0.1909, (C) 0.2155 , and (D) 0.4162 .

the data for the cross-linking reactions at different substrate concentrations were plotted as a graph of normalized absorbance $\left(A(t) / A_{0}\right)$ (Figure 7$)$. When the reaction rates were assessed as the amount of FA consumed per minute $\left(\mu \mathrm{M} \mathrm{min}^{-1}\right)$, it became evident that the initial reaction rates increased with increased FA substrate concentration and, moreover, that the reaction rates of Ara 1 and Ara2 in general were several-fold higher than the reaction rates of samples Ara1b and Ara2b (Figure 8). Hence, at similar FA concentrations of, for example, $20 \mu \mathrm{M}$, the rates of cross-linking for Ara1 and Ara2 were 5.6 and $4.1 \mu \mathrm{M} \mathrm{min}^{-1}$, respectively, and thus statistically significantly higher $(P<0.05)$ than the rates of crosslinking for the longer chain arabinans, which were approximately 5 times slower at 0.94 and $0.78 \mu \mathrm{M} \min ^{-1}$ for Ara1b and Ara2b, respectively (Figure 8). Due to the fast reaction rates for Ara1 and Ara2, rates were calculated from the slope of the decreasing absorbance for the first $10 \mathrm{~s}$, whereas for Ara1b and Ara2b the rates were calculated for the first minute of the cross-linking reaction due to absorbance fluctuation in the first few minutes of the longer chain cross-linking reactions (Figure 7C,D). At the relatively low FA levels, from 2.5 to $10 \mu \mathrm{M}$, the reaction rates of Ara1 and Ara2 were similar and ranged from $\sim 1.5$ to $3.0 \mu \mathrm{M} \mathrm{min}^{-1}$. The reaction rates of the Ara1b and Ara2b substrates were also similar, even from 2.5 to $20 \mu \mathrm{M}$, and ranged from 0 to $0.4 \mu \mathrm{M} \mathrm{min}^{-1}$ (Figure 8). At higher substrate concentration, the reaction rates of the pairs of Aral and Aralb were significantly higher $(P<0.05)$ than those of Ara2 and Ara2b. Apart from Aralb having a higher content of the relatively shorter arabinans, of molecular weight $1.3 \mathrm{kDa}$, than the Ara2b sample (Figure 6), it was not possible to relate the differences in the rates directly to the subtle differences in the molecular weight profiles among the pairs of shorter arabinans Aral and Ara2 and among the longer chain arabinan samples Ara1b and Ara2b, respectively. The data did indicate, however, that the "zipping" between FAs in the arabinan to form diFAs was very slow and increased less with increased FA concentration in the longer chain arabinans than in the shorter, probably due to the limited access of FA for the cross-linking to occur. It appeared to be more difficult to initiate the reaction between the FA on the longer chains than on the shorter arabinan chains, corroborating the interpretation that longer chains react more slowly as illustrated in Figure 1. Hence, the overall result that the cross-linking rates of the longer chain (feruloylated) arabinans were much slower than the corresponding rates of the shorter (feruloylated) arabinans when reacted at the same FA concentration supported the hypothesis that the rate of cross-linking is affected by the extent of the backbone length of the arabinan.

Formation of Ferulic Acid Dehydrodimers. Enzymatic cross-linking of FA was an oxidative reaction that produced feruloyl dehydrodimers $\left(5,5^{\prime}, 8-O-4^{\prime}\right.$, and $8,5^{\prime}$ benzofuran-diFA). Disappearance of FA and formation of diFAs from the crosslinking reaction was further confirmed by HPLC analysis (Table 1 and Figure 9), which is in complete agreement with previous studies. ${ }^{8,9}$ Of the diFAs identified, the $8,5^{\prime}$-diFA and 8-O-4'-diFA forms predominated, with traces of 5,5'-diFA detected (Figure 9). A minimal peak was observed at the retention time equivalent to $8,8^{\prime}$-diFA, but the level was too low to be quantified. It has been reported that $8,8^{\prime}$-diFA is one of the most favorable forms resulting from the oxidative cross-linking 
of FA with different peroxidases and laccases in arabinoxylan, ${ }^{21}$ whereas in pectic polysaccharides, $8-O-4^{\prime}$ and $8,5^{\prime}$-diFA appear to dominate. ${ }^{9}$ As suggested in the previous study, ${ }^{21}$ one of the possibilities that the $8,8^{\prime}$-diFA form was not detected in the analysis of the cross-linked arabinan might be due to its transient properties and involvement in further polymerization to form more complex dehydropolymers. However, it has previously been reported that $8,8^{\prime}$-diFA can be found in pectic polysaccharides with a small decrease after the addition of HRP and $\mathrm{H}_{2} \mathrm{O}_{2}$.

Among the different types of substrate samples, the amount of 8,5-diFA increased significantly in Aral and with a lower relative increase in the $5,5^{\prime}$-diFA form by cross-linking (35\%) and no change in the 8-O-4'-diFA (Figure 9A). A similar pattern was evident for Ara2 and Ara1b, whereas Ara2b deviated somewhat from this trend as the levels of all three types of diFAs in fact decreased after cross-linking (Figure 9D). We interpret the decrease in diFAs in Ara2b as being due to the oxidation by excess $\mathrm{H}_{2} \mathrm{O}_{2}$ because the $\mathrm{H}_{2} \mathrm{O}_{2}$ :FA level was relatively higher for Ara2b due to the low FA levels in this sample (Figure 9D). Reaction with a further excess amount of $\mathrm{H}_{2} \mathrm{O}_{2}$ caused a significantly decreased level of FA but no increase in diFAs (data not shown). This is because a higher ratio of $\mathrm{H}_{2} \mathrm{O}_{2} / \mathrm{FA}$ in the reaction caused a higher extent of oxidation of FA and diFAs and, hence, reduced the amount of diFAs as well. A previous study also reported a decrease in oligomerization with higher ratios of $\mathrm{H}_{2} \mathrm{O}_{2} / \mathrm{FA}$, possibly because higher amounts of $\mathrm{H}_{2} \mathrm{O}_{2}$ led to partial inactivation of the enzyme. $^{20}$ There is also a possibility that a portion of the FA and natural occurring diFAs was converted to other products not detectable by the HPLC method employed, for example, trimers or tetramers. ${ }^{20,22}$ The latter types of reactions may in any case explain the imbalanced total amount of FA and diFAs before and after the cross-linking as such reactions have been reported previously to cause deviations in the stoichiometry of cross-linking reactions of FA to diFAs. ${ }^{23}$ In this study, a few unidentified peaks did occur on the chromatograms after crosslinking. The spectra (UV-vis) were similar to the spectra of trimers reported, ${ }^{24}$ but our analysis did not allow a firm identification or quantification of these compounds.

It may be speculated that the hypothesis that the length of the arabinan backbone influenced the kinetics of the cross-linking was an oversimplification of the events, but the results nevertheless confirmed this initial hypothesis. Hence, it was proven that the rate of FA cross-linking depends on the arabinan oligosaccharide backbone chain length; that is, longer arabinans exhibit a slower cross-linking rate than shorter arabinans, all other things being equal. It is not only the substrate concentration but also the molecular size, that is, the arabinan backbone chain length, that affects the rate of cross-linking. For further investigation, this work will be used as a basis to investigate how the rates of enzyme-catalyzed cross-linking affect the rates of gelation and the resulting gel strength.

\section{AUTHOR INFORMATION}

\section{Corresponding Author}

*Phone: +45 4525 2800. E-mail: am@kt.dtu.dk.

\section{Funding Sources}

We acknowledge Universiti Teknologi Malaysia, Skudai, and the Ministry of Higher Education, Malaysia, for their financial support.

\section{ACKNOWLEDGMENT}

We acknowledge Danisco A/S for supplying the materials for this study and Southern Danish University for performing the MALDI-TOF/TOF analysis.

\section{ABBREVIATIONS USED}

Ara, arabinan; diFAs, ferulic acid dehydrodimers; DP, degree of polymerization; FA, ferulic acid groups; HRP, horseradish peroxidase; $\mathrm{H}_{2} \mathrm{O}_{2}$, hydrogen peroxide; $\mathrm{NaOH}$, sodium hydroxide; $\mathrm{NaH}_{2} \mathrm{PO}_{4} \cdot \mathrm{H}_{2} \mathrm{O}$, sodium dihydrogen phosphate monohydrate; $\mathrm{Na}_{2} \mathrm{HPO}_{4}$, disodium hydrogen phosphate; $\mathrm{Na}_{2} \mathrm{SO}_{4}$, anhydrous sodium sulfate.

\section{REFERENCES}

(1) Oosterveld, A.; Beldman, G.; Schols, H. A.; Voragen, A. G. J. Characterization of arabinose and ferulic acid rich pectic polysaccharides and hemicelluloses from sugar beet pulp. Carbohydr. Res. 2000, 328, 185-197.

(2) Holck, J.; Hjernø, K.; Lorentzen, A.; Vigsnæs, L. K.; Hemmingsen, L.; Licht, T. R.; Mikkelsen, J. D.; Meyer, A. S. Tailored enzymatic production of oligosaccharides from sugar beet pectin and evidence of differential effects of a single DP chain length difference on human faecal microbiota composition after in vitro fermentation. Process Biochem. 2011, 46, 1039-1049.

(3) Westphal, Y.; Khnel, S.; de Waard, P.; Hinz, S. W. A.; Schols, H. A.; Voragen, A. G. J.; Gruppen, H. Branched arabino-oligosaccharides isolated from sugar beet arabinan. Carbohydr. Res. 2010, 245, 1180-1189.

(4) Levigne, S. V.; Ralet, M.-C. J.; Quéméner, B. C.; Pollet, B. N.-L.; Lapierre, C.; Thibault, J.-F. J. Isolation from sugar beet cell walls of arabinan oligosaccharides esterified by two ferulic acid monomers. Plant Physiol. 2004, 134, 1173-1180.

(5) Saulnier, L.; Thibault, J. Ferulic acid and diferulic acids as components of sugar-beet pectins and maize bran heteroxylans. J. Sci. Food Agric. 1999, 402, 396-402.

(6) Colquhoun, I. J.; Ralet, M. C.; Thibault, J. F.; Faulds, C. B.; Williamson, G. Structure identification of feruloylated oligosaccharides from sugar beet pulp by NMR spectroscopy. Carbohydr. Res. 1994, 263, 243-256.

(7) Micard, V.; Thibault, J. F. Oxidative gelation of sugar-beet pectins: use of laccases and hydration properties of the cross-linked pectins. Carbohydr. Polym. 1999, 39, 265-273.

(8) Oosterveld, A.; Beldman, G.; Voragen, A. G. J. Oxidative crosslinking of pectic polysaccharides from sugar beet pulp. Carbohydr. Res. 2000, 328, 199-207.

(9) Oosterveld, A.; Grabber, J. H.; Beldman, G.; Ralph, J.; Voragen, A. G. J. Formation of ferulic acid dehydrodimers through oxidative crosslinking of sugar beet pectin. Carbohydr. Res. 1997, 300, 179-181.

(10) Waldron, K. W.; Ng, A.; Parker, M. L.; Parr, A. J. Ferulic acid dehydrodimers in the cell walls of Beta vulgaris and their possible role in texture. J. Sci. Food Agric. 1997, 74, 221-228.

(11) Kuuva, T.; Lantto, R.; Reinikainen, T.; Buchert, J.; Autio, K. Rheological properties of laccase-induced sugar beet pectin gels. Food Hydrocolloids 2003, 17, 679-684.

(12) Arnous, A.; Meyer, A. S. Comparison of methods for compositional characterization of grape (Vitis vinifera L.) and apple (Malus domestica) skins. Food Bioprod. Process. 2008, 86, 79-86.

(13) Rasmussen, L. E.; Sørensen, J. F.; Meyer, A. S. Kinetics and substrate selectivity of a Triticum aestivum xylanase inhibitor (TAXI) resistant D11F variant of Bacillus subtilis XynA xylanase. J. Biotechnol. 2010, 146, 207-214.

(14) Andreasen, M. F.; Christensen, L. P.; Meyer, A. S.; Hansen, Å. Release of hydroxycinnamic and hydroxybenzoic acids in rye by commercial plant cell wall degrading enzyme preparations. J. Sci. Food Agric. 1999, 7, 411-413. 
(15) Andreasen, M. F.; Christensen, L. P.; Meyer, A. S.; Hansen, Å. Content of phenolic acids and ferulic acid dehydrodimers in 17 rye (Secale cereale L.) varieties. J. Agric. Food Chem. 2000, 48, 2837-2842.

(16) Agger, J.; Viksø-Nielsen, A.; Meyer, A. S. Enzymatic xylose release from pretreated corn bran arabinoxylan: differential effects of deacetylation and deferuloylation on insoluble and soluble substrate fractions. J. Agric. Food Chem. 2010, 58, 6141-6148.

(17) Waldron, K. W.; Parr, A. J.; Ng, A.; Ralph, J. Cell wall esterified phenolic dimers: Identification and quantification by reverse phase high performance liquid chromatography and diode array detection. Phytochem. Anal. 1996, 7, 305-312.

(18) Rasmussen, L. E.; Meyer, A. S. Size exclusion chromatography for the quantitative profiling of the enzyme-catalyzed hydrolysis of xylooligosaccharides. J. Agric. Food Chem. 2010, 58, 762-769.

(19) Holck, J.; Lorentzen, A.; Vigsnæs, L. K.; Licht, T. R.; Mikkelsen, J. D.; Meyer, A. S. Feruloylated and nonferuloylated arabino-oligosaccharides from sugar beet pectin selectively stimulate the growth of Bifidobacterium spp. in human fecal in vitro fermentations. J. Agric. Food Chem. 2011, 59, 6511-6519.

(20) Bunzel, M.; Heuermann, B.; Kim, H.; Ralph, J. Peroxidasecatalyzed oligomerization of ferulic acid esters. J. Agric. Food Chem. 2008, 56, 10368-10375.

(21) Robertson, J. A.; Faulds, C. B.; Smith, A. C.; Waldron, K. W. Peroxidase-mediated oxidative cross-linking and its potential to modify mechanical properties in water-soluble polysaccharide extracts and cereal grain residues. J. Agric. Food Chem. 2008, 56, 1720-1726.

(22) Bunzel, M.; Ralph, J.; Steinhart, H. Phenolic compounds as cross-links of plant derived polysaccharides. Czech J. Food Sci. 2004, 22, 64-67.

(23) Bunzel, M.; Ralph, J.; Funk, C.; Steinhart, H. Isolation and identification of a ferulic acid dehydrotrimer from saponified maize bran insoluble fiber. Eur. Food Res. Technol. 2003, 217, 128-133.

(24) Bunzel, M.; Ralph, J.; Funk, C.; Steinhart, H. Structural elucidation of new ferulic acid-containing phenolic dimers and trimers isolated from maize bran. Tetrahedron Lett. 2005, 46, 5845-5850. 